\title{
DAVID CRONENBERG, AUTOR DE ALMOÇO NU: A TRADUÇÃO INTERSEMIÓTICA COMO TRANSCRIAÇÃO
}

\author{
Rosângela Fachel de Medeiros* \\ Universidade Regional Integrada do Alto Uruguai e das Missões
}

\begin{abstract}
Resumo: Esse artigo apresenta e analisa o processo de tradução intersemiótica realizada pelo cineasta David Cronenberg do romance Almoço $\mathrm{Nu}$, de William Burroughs, e as bifurcações intertextuais implicadas nesse processo. Investigando as aproximações e distanciamentos existentes entre os universos criativos dos dois artistas e como eles se ressignificam mutuamente. Para tanto, são utilizados como aporte teóricos a ideia da transcriação, proposta por Haroldo de Campos, e a noção do tradutor enquanto leitor proposta por Jorge Luis Borges.
\end{abstract}

Palavras-chave: Tradução intersemiótica. Cinema. Literatura. David Cronenberg. William Burroughs.

\section{DAVID CRONENBERG, AUTHOR OF NAKED LUNCH: INTERSEMIOTIC TRANSLATION AS TRANSCREATION}

\begin{abstract}
This paper presents and analyzes the intersemiotic translation process performed by filmmaker David Cronenberg of William Burroughs' novel Naked Lunch, and the intertextual bifurcations involved in this process. Investigating the similarities and differences between the
\end{abstract}

\footnotetext{
* Possui graduação em Comunicação Social pela Pontifícia Universidade Católica do Rio Grande do Sul (1993), mestrado (2002) e doutorado (2008) em Teoria Literária - Literatura Comparada pela Universidade Federal do Rio Grande do Sul (UFRGS). Atualmente é professora do Mestrado em Letras - Literatura Comparada na Universidade Regional Integrada do Alto Uruguai e das Missões. Frederico Westphalen, Rio Grande do Sul, Brasil. Email: rosangelafachel@gmail.com.
} 
creative worlds of both artists and how they reframe each other. For this, are used as the theoretical the idea of transcreation proposed by Haroldo de Campos, and the notion of the translator as a reader proposed by Jorge Luis Borges.

Keywords: Intersemiotic translation. Cinema. Literature. David Cronenberg. William Burroughs.

\section{David Cronenberg, um cineasta que reescreve: do texto ao filme}

A ideia de adaptar Almoço nu (Naked Lunch - 1959), de Williams Burroughs, revela a ousadia de David Cronenberg ao se aventurar por uma obra a que todos se referiam como "infilmável".${ }^{1}$ Ação que conflui com a percepção de Haroldo de Campos de que quanto mais inçado de dificuldades o texto, "mais recriável, mais sedutor enquanto possibilidade aberta à recriação" (CAMPOS, 1992, p. 35), sendo essa uma "operação radical da tradução" (SANTAELLA, 2005, p. 224), que ele concebeu como transcriação. O livro de Burroughs é composto por uma coleção de fragmentos, denominados pelo escritor de "rotinas", que parecem ter sido criados individualmente e só, posteriormente, terem sido reunidos através de colagens, havendo alguns textos que se relacionam entre si e personagens recorrentes. E apesar de serem textos em formato de esquetes semelhantes a monólogos ou a diálogos, o que lhes concede um teor de teatralidade, é difícil pensar no livro como uma obra para ser levada à tela ou ao palco. O impetuoso projeto de adaptação nasceu em 1983 em Cannes. Contudo, o roteiro só foi finalizado em 1989 e o filme foi lançando em 1991. Cronenberg manteve o título do livro para o filme e deu esse mesmo título ao

\footnotetext{
${ }^{1}$ No Brasil, o filme recebeu o título Mistérios e paixões, para manter a homogeneidade no interior do texto, este será o título utilizado quando se estiver referindo ao filme. E para designar o livro, será utilizado o título da tradução em português: Almoço nu.
} 
livro que seu protagonista está escrevendo. Além disso, o cineasta mantém o nome de alguns personagens e algumas passagens do livro são citadas diretamente, mas em um contexto narrativo diferente, pois no texto de Burroughs não há uma narrativa continua.

\section{A vida de Burroughs como intertexto do filme}

Em 1951, Burroughs matou acidentalmente sua esposa Joan com um tiro na cabeça quando, ambos drogados, brincavam de "Guilherme Tell". Após o incidente, o escritor viajou pela América do Sul, passou algum tempo em Nova Iorque e acabou ficando um tempo no Tânger, em 1953, onde escreveu os textos que viriam a ser, posteriormente, agrupados e publicados sob o título de Almoço пи. Esses episódios de sua biografia foram recriados no filme de Cronenberg como episódios da vida do protagonista que se imbricam a situações retiradas do livro. Uma interessante releitura do cineasta, uma vez que, apesar de Burroughs não fazer alusão em seus textos à morte da esposa, ao retomar os manuscritos de Queer, escrito após o incidente, para publicá-lo vinte anos depois, ele confessa que se sentia impedido de lê-lo, pois: "the book is motivated and formed by an event which is never mentioned, in fact is carefully avoided: the accidental shooting death of my wife, Joan, in September 1951. [...] I would never have become a writer but for Joan's death" (BURROUGHS apud BEARD, 2006, p. 284). A criação da personagem Joan Lee, baseada na figura da esposa de Burroughs, referida de forma oblíqua e secundária na introdução de Queer, e sua importância na trama, uma vez que é sua morte o episódio norteador do filme, revelam a leitura e a apropriação que o cineasta realiza de elementos extratextuais em seu processo de transcriação do texto-fonte. Nesse sentido, a conturbada e entorpecida estada de Burroughs no Tanger, durante o tempo em que escrevia o romance, é apresentada no filme como uma prolongada alucinação literária, que transforma a exótica cidade do Marrocos em Interzona. E o fato de não poder filmar no Tanger levou Cro- 
nenberg a recriar cenograficamente a cidade como um estado mental, transfigurado na fictícia Interzona, carregada do imaginário de exotismo árabe.

A trama do filme entrecruza dois lugares, a Nova Iorque dos anos 1950 e a fictícia Interzona. Já no início do filme, caracteres sobrepostos à imagem localizam a narrativa no espaço e no tempo: "Cidade de Nova Iorque - 1953." Contudo, a Nova Iorque do filme tem um ar fantástico: suas cores escuras e os lugares pouco iluminados evocam o clima do cinema $n o i^{2}$ de mistério, conspirações e assassinatos; que se prolonga também para a Interzone. E, como em todo noir, é a lógica da investigação e do complô que rege a relação do protagonista com o mundo. Os lugares de Nova Iorque replicados na Interzona, como quando Lee entra em um restaurante na Interzona e comenta que há um restaurante igual em Nova Iorque, revelam que Lee, ao contrário de Burroughs, jamais deixou Nova Iorque e que a Interzona é uma alucinação de sua mente alterada pelas drogas. Assim também, os personagens que aparecem em Nova Iorque possuem duplos na Interzona, que são interpretados pelos mesmos atores. Joan Lee, que morrera em Nova Iorque, reaparece como Joan Frost em Interzona (e a semelhança entre elas faz com que Joan Frost seja uma assombração

${ }^{2} \mathrm{O}$ termo filme noir foi utilizado pela primeira vez pelo crítico francês Nino Frank, em 1946, como derivação da expressão romance noir, para designar filmes que apresentavam características recorrentes desses romances, textos policiais e de suspense que se tornaram populares nos EUA na época da Grande Depressão. A partir da década de 1940, muitos desses livros foram adaptados por Hollywood e, chegando à Europa, foi natural que receberem a mesma denominação. Esses filmes também sofreram influência do "realismo" do cinema francês e da estética do expressionismo cinematográfico alemão. Visualmente apresentam um código bem específico que é a utilização do chiaroscuro (contraste entre claro e escuro). $\mathrm{E}$, apesar de ser difícil definir um conceito geral para o gênero, geralmente, há crime no centro da trama e que tem relação a uma femme-fatale. A designação, filme noir, surgiu posteriormente à realização dos grandes clássicos do gênero como: O falcão maltês (The Maltese Falcon - 1941), A dama de Xangai (The Lady from Shanghai - 1947), Crepúsculo dos deuses (Sunset Boulevard - 1950). O cinema noir influenciou muitos cineastas e foi relido pelo chamado new-noir como em Chinatown - 1974, de Roman Polanski. 
para Lee, como uma lembrança constante da esposa morta); o Dr. Benway de Nova Iorque se transforma em Fadela na Interzona; e os mesmos atores interpretam os policiais que interrogam Lee em Nova Iorque e os guardas de fronteira que o interpelam ao sair de Interzona. Essa duplicidade reforça o jogo de deslizamento entre biografia e ficção presente na criação do filme, que mistura trechos de textos e dados biográficos de Burroughs.

Se no livro não há um protagonista, no filme, ele é William (Bill) Lee (interpretado por Peter Weller) ${ }^{3}$ mesmo nome de um dos personagens do livro, que pode ser visto ainda como um pseudônimo do escritor, pois Lee, sobrenome da mãe de Burroughs, foi utilizado por ele para assinar seu primeiro livro, Junk: Confessions of an Unredeemed Drug Addict (1953). William Lee foi também o nome escolhido para o protagonista de seu segundo livro: Queer. E foi em Queer que Cronenberg buscou a essência de seu protagonista, personagem criado da combinação de elementos biográficos do escritor a elementos de seus personagens. Além disso, todo material que é retirado diretamente dos livros de Burroughs, citações ou trechos de diálogos, é colocado na boca de Lee. O fascínio do cineasta pela figura do escritor, por sua vida, suas experiências e suas ideias, originou ainda outra personagem, uma representação física do Burroughs contemporâneo ao filme, um velho junky; Edward, um veterano exterminador de insetos, descarnado e corroído pelo vício. Assim, quando Lee encontra Edward é como se ele pudesse encontrar a si mesmo já velho e desgastado pelos vícios, e a voz grave e áspera do velho é a mesma voz de todas as criaturas das alucinações de Lee, sugerindo que todos são versões de Burroughs que Cronenberg coloca em interação.

\footnotetext{
${ }^{3}$ Peter Weller, que fora um músico de jazz profissional e é admirador do romance de Burroughs e fã da geração beat, soube do projeto de Cronenberg e lhe escreveu oferecendo-se para fazer o papel do protagonista. Sua atuação em Mistérios e paixões é, com certeza, um dos pontos altos de sua carreira. Até então seu trabalho mais notório fora protagonizar o filme RoboCop (1987), de Peter Verhoeven, e sua seqüência Robocop II (1990), de Irvin Kershner, abstendo-se de participar do terceiro filme da série para estrelar o filme de Cronenberg.
} 
Contudo, também os eventos biográficos apresentados no filme estão distorcidos e se misturam às alucinações do personagem. Assim é com a morte Joan Lee que é associada ao início da atividade literária de Lee, que após o ocorrido vai a um bar gay onde é apresentado ao Mugwump, especialista em "ambivalência sexual”, que o impele a escrever um relatório sobre o incidente. Maneira encontrada pelo cineasta para salientar sua visão do processo criador do escritor protagonista, responsável pela transformação de sua própria realidade, tema recorrente na filmografia de Cronenberg.

\section{Sobre moscas, baratas e outros insetos}

Mais que uma adaptação de Almoço nu, o filme de Cronenberg é uma materialização de sua forte relação com a figura de Burroughs e com sua obra. E a escolha em começar o filme com um episódio do conto "Exterminator!", tendo o próprio Burroughs trabalhado como exterminador, desvela a perspectiva do cineasta de construir o filme a partir da confluência entre sua obra e a do escritor. Uma vez que os insetos são uma obsessão para ambos, no entanto, em perspectivas antagônicas, como destaca o cineasta:

His approach to insects is somewhat different from mine, and it figures prominently in the script. He usually uses that as a negative feature - you know, if he says someone has 'blank, insect eyes,' or an 'insect voice,' that's usually meant to mean soulless, inhuman. I sometimes find some kind of attractive otherworldliness about insect (CRONENBERG apud BEARD, 2006, p. 529).

A repulsa de Burroughs está na origem de seu pensamento conspiratório de que os seres humanos são controlados por insetos alienígenas gigantes. Ideia transformada por Cronenberg no tema 
central do mergulho de Lee na Interzona como um agente infiltrado controlado por criaturas alienígenas.

Já nesse primeiro episódio, Cronenberg apresenta sua marca de tradutor/autor, ao eleger o conto e criar um protagonista exterminador de baratas, escolhendo algo do universo do escritor que se aproxima a seu próprio imaginário, o fascínio pelos insetos. Questão que já levara ao extremo em $A$ mosca, apresentando a mutação de seu portagonista, Seth Brundle, em um híbrido homem-mosca. O híbrido é uma figura recorrente em seu cinema chegando em Mistérios e paixões à hibridação orgânico-inorgânico, carne-tecnologia, dos "besouros-máquinas de escrever", seres gerados da interação de seu imaginário ao de Burroughs, uma vez que não existem no texto do escritor.

Tais criaturas povoam as alucinações de Lee como uma metáfora no filme do poder assustador do fazer literário, que está associado à energia e aos impulsos sexuais, tanto hetero como homossexuais, tendo a literatura poderes afrodisíacos, sexo e literatura estão imbricados. Como evidencia o episódio em que Lee, ao retornar para casa, encontra a esposa fazendo sexo com seu amigo Hank enquanto seu outro amigo Martin lê um texto manuscrito que é, na verdade, um trecho de Almoço nu. E quando ele pergunta à esposa se ela teve um orgasmo, ela responde que é viciada em inseticida e não precisa gozar, pois a droga gera algo muito mais intenso: "um 'barato literário, bastante literário [...] um 'barato' kafkiano. A gente se sente como um inseto" (transcrito do filme). Para não experimentar a droga, Lee argumenta que seus metabolismos são diferentes e Joan lhe pergunta ironicamente: "o seu e o de Kafka?”. Mas Lee acaba cedendo ao 'barato' literário kafkiano gerado pelo inseticida e em suas alucinações encontra-se com um inseto gigante, que diz ser seu oficial e o encarrega de matar a própria esposa.

Ao evocar Kafka, Cronenberg traz a obra do escritor tcheco como intertexto para o filme, colocando-a em diálogo com a obra de Burroughs e evidenciando, assim, uma leitura comparada que as entrecruza. Ao referir Kafka, o cineasta evoca seu texto mais 
conhecido, "A metamorfose", ${ }^{4}$ e ressignifica a experiência kafkiana terrível de sentir-se como um inseto, transformando-a em um estado mental que ativa a criação literária; pois é quando Lee está impregnado desse sentimento, que o influxo literário se manifesta. No entanto, ao evocar o conto, o cineasta não se refere à experiência vivida pelo personagem, Gregor Samsa, mas ao próprio Kafka, imbricando, novamente, a vida do escritor à sua obra. Cronenberg traz para o filme não apenas o intertexto literário, mas também elementos biográficos e psicológicos do escritor. A figura de Kafka é tão ou mais importante no discurso cronenberguiano do que sua obra. E, mais uma vez, a inquietação do cineasta se direciona às condições que colaboraram para a realização literária:

Kafka could write his stories in the context that he was in his time. [...] Perhaps Kafka would have been destroyed by being successful; his sensibility was driven by paranoia, loneliness and despair. [...] I don't know if Kafka had any social skills; he was an alien, alien, alien. He was a Jew and a German-speaker in a Czech city. He was just wrong (CRONENBERG, 1997, p. 16).

Kafka integra a galeria de escritores outsiders cultuados por Cronenberg. Assim, além da figura de Burroughs também a de Kafka é utilizada para compor o protagonista do filme, apresentando sua leitura da relação entre obras e escritores, lidos quase como personagens.

\footnotetext{
${ }^{4}$ Não por acaso, Cronenberg é o autor do texto de introdução da tradução mais recente de "A metamorfose" (2014) para o inglês, realizada por Susan Bernofsky. Nesse texto, o cineasta relaciona o texto de Kafka a seu filme, A mosca.
} 


\section{Da metáfora literária ao efeito especial cinematográfico}

Uma dificuldade referida por Cronenberg quanto ao processo de adaptação é encontrar o correspondente cinematográfico para uma metáfora literária (CRONENBERG, 1992, p. 12). Em Mistérios e paixões, os efeitos especiais surgiram para atender o roteiro que buscou recriar o universo de ficção científica e de horror conspiratório da obra de Burroughs, dando vida às alucinações literárias de Lee e a suas criaturas surreais: besouros gigantes falantes que acabam por se combinar à tecnologia da máquina de escrever se metamorfoseando em seres híbridos inseto-máquina; os enormes Mugwumps, cuja forma humanoide apresenta características de réptil; e uma monstruosa centopeia gigante com rosto humano. Os Mugwumps foram retirados diretamente de Almoço $n u$, mas Cronenberg os transforma em velhos junkies, buscando inclusive alguns traços físicos do próprio Burroughs. Criaturas pacíficas, os Mugwumps acabam escravizados em uma espécie de fábrica para a coleta do fluido leitoso e alucinógeno que é expelido pelos tentáculos que têm em sua cabeça. O consumo dessa substância está diretamente conectado à produção literária de Lee. E essa relação com o processo criativo é ressaltada ainda pelo aparecimento de uma cabeça de Mugwump que é também uma máquina de escrever. A criação literária está então associada ao consumo de drogas, todas inventadas pelo cineasta: o inseticida, o líquido leitoso vertido pelos Mugwumps e a substância preta produzida de centopeias gigantes do Brasil; e ao prazer sexual.

Os efeitos especiais servem, então, para criar as alucinações-literárias de Lee, construindo uma realidade alternativa na qual ele confronta suas inquietações. No entanto, o vício nas substancias que lhe causam as alucinações e o levam à literatura, o deixa à mercê daqueles que as controlam. As drogas nos textos de Burroughs funcionam, assim, da mesma forma que os vírus nos filmes de Cronenberg, como algo perigoso, mas atraente, que é um agente poderoso de transformação, confluindo ambas as obras para a abordagem do vício, da manipulação e do controle. Como nas conspirações ad- 
ministradas por corporações misteriosas que são uma marca dos primeiros filmes de Cronenberg e são recorrentes na obra de Burroughs, repleta de teorias de conspiração e de controle, exercidas por seres alienígenas ou pré-históricos, que implantam mecanismos psicológicos malignos de controle do prazer tanto relacionado ao sexo quanto às drogas. Uma metáfora do poder exercido sobre o dependente por traficantes e policiais no que Burroughs definiu como "álgebra da necessidade": a forma como o desejo pelas drogas suplanta todos os outros desejos e objetivos e leva à decadência física, facilitando a manipulação e o controle do viciado.

\title{
A (in)confluência dos imaginários sexuais
}

A maior citação do texto no filme é o episódio do "ânus falante" ("The Talking Asshole"), que é contado ipsis litteris por Lee a seus amigos:

\begin{abstract}
After a while, the ass started talking on its own. [...] Finally, it talked all the time, day and night. You could hear him for blocks, screaming at it to shut up, and beating it with his fist, and sticking candles up it. But nothing did any good, and the asshole said to him, "It's you who will shut up in the end, not me. Because, we don't need you around here any more. I can talk, and eat, AND shit". [...] For awhile, you could see the silent helpless suffering of the brain behind the eyes, then finally the brain must have died, because the eyes went out, and there was no more feeling in them than a crab's eye on the end of a stalk. (BURROUGHS, 2001, p. 110).
\end{abstract}

A história da disputa do homem com seu ânus pelo domínio do corpo pode ser lida como metáfora do conflito do personagem em assumir sua homossexualidade. E a escolha do cineasta por esse episódio do livro revela o desejo de imbricar sua obra à do escritor 
através da seleção de trechos que, segundo o próprio, ele mesmo poderia ter escrito:

\begin{abstract}
El ano parlante es una imagen muy literal del tabú de los orificios humanos. Es una de las contribuciones más infames de Burroughs a la literatura, que toca algo sensible: encontrar a través de la organización de nuestros cuerpos y de nuestras vidas las formas de representación específicas y aceptables. (CRONENBERG apud GOROSTIZA, 2003, p. 233).
\end{abstract}

A interpretação que Cronenberg faz do episódio remete às suas próprias inquietações em relação ao corpo e suas possibilidades de transformação, que resulta em várias imagens de novos orifícios criados no corpo humano: fendas semelhantes à vagina, em Videodrome e em Crash; e orifícios semelhantes ao ânus, em Enraivecida na fúria do sexo e eXistenZ; que surgem como uma reflexão do cineasta acerca de uma nova sexualidade para além dos órgãos sexuais.

Em Mistérios e Paixões há recorrentes alusões à imagem do ânus representado pelo orifício nas costas do inseto gigante através do qual ele fala com Bill Lee, configurando-se literalmente como um "ânus falante". Além disso, o ânus representa um ponto de indistinção entre a anatomia masculina e feminina, outra questão recorrente na obra de Cronenberg. Que, em seus filmes, apresenta quase sempre os intercursos hetero e homossexuais em posições de penetração por trás, destacando a indistinção sexual da penetração anal. E, em eXistenZ, os bioports, orifícios semelhantes ao ânus criados nos corpos dos jogadores bem ao final da espinha dorsal para conectá-los ao jogo, equiparam homens e mulheres, que podem igualmente penetrar e ser penetrados. A ideia de que esses bioports inauguram possibilidades de prazer associadas à penetração anal é reforçada pelo prazer demonstrado pelos personagens ao estarem conectados ao jogo através desse orifício. 
Mas apesar das imagens apresentadas por Cronenberg confrontarem tabus sexuais, Almoço $\mathrm{Nu}$ foi criticado por não apresentar a homossexualidade predadora do texto de Burroughs. Apesar de mostrar a homossexualidade, tomando como referência a biografia de Burroughs, a questão é apresentada de forma ambígua e ambivalente, buscando retratar a angústia de seu protagonista em lidar com sua sexualidade. Uma vez que a homossexualidade apresentada nos textos literários de Burroughs não está, por exemplo, em suas cartas. No filme, a criatura inseto-máquina-de-escrever dá voz aos desejos transgressivos do protagonista e, falando por sua boca -ânus, sugere a homossexualidade como disfarce para as atividades de espionagem de Lee:

O homossexualismo é o melhor disfarce para um agente. [...] Nós avaliamos que você poderia achar a ideia de engajar-se em atos homossexuais imoral e talvez fisicamente repulsiva, mas estamos convencidos de que você poderá superar estas barreiras pessoais para melhor servir à causa a qual nos devotamos. (transcrito do filme, 37min19s)

A criatura surge como um duplo do protagonista, dando voz aos seus pensamentos paranóicos e misóginos mais íntimos enquanto seu desejo homossexual, apesar de reprimido, aumenta. À medida que adentra esse universo alucinatório literário o desejo homossexual de Lee aflora, mas sempre de forma conflituosa, sendo os intercursos homossexuais representados de forma assustadora. E apesar de ocorrerem situações de desejo heterossexual, em Interzona é como se tudo levasse ao desejo homossexual que é reprimido em bizarras situações surreais. Nesse sentido, Burroughs aponta a diferença entre a visão de Cronenberg e a sua: David chose to treat "Lee's" homosexuality as a somewhat unwelcome accident of circumstance and plot, rather than as an innate characteristic. (BURROUGHS apud BEARD, 2006, p. 323). 


\section{David Cronenberg, autor de Almoço nu: transcriação e reescritura}

Para David Cronenberg, "as linguagens do cinema e da literatura se completam, e até mesmo se alimentam uma da outra", sendo "impossível julgar uma em relação à outra" (CRONENBERG apud TIRARD, 2006, p. 195), no entanto, ele entende que there are things you can do in writing that you simply cannot do in cinema and vice versa. I don't think one supplants the other, ideally they enhance, reflect each other (CRONENBERG, 1997, p. 98). Confluindo assim com Linda Hutcheon (2011) em sua reflexão a respeito da adaptação de obras literárias, de que sempre deve ser levado em consideração o fato de que cada arte possui potencialidades específicas. Nesse sentido, "a adaptação é um tipo de palimpsesto extensivo, e com frequência, ao mesmo tempo, uma transcodificação para um diferente conjunto de convenções" (HUTCHEON, 2011, p. 61). Essa transcodificação de um determinado sistema de signos para outro sistema semiótico (não apenas do literário para o cinematográfico) é reconhecida como tradução intersemiótica (PLAZA, 1987). E, no caso do cineasta, a compreensão das relações entre as duas linguagens, com suas confluências e distanciamentos, advém de sua experiência com ambas, inclusive adaptando textos literários. ${ }^{5}$

O processo de adaptação realizado por Cronenberg para chegar a Mistérios e paixões pode ser comparado ao processo de Pierre

\footnotetext{
${ }^{5}$ Cronenberg foi coautor do roteiro de $A$ mosca e de Gêmeos: mórbida semelhan$c ̧ a$, ambos originados de obras literárias. $A$ mosca é uma adaptação do conto $A$ mosca (1957), de George Langelaan, que foi também o ponto de partida de $A$ mosca da cabeça branca (1958), de Kurt Neumann. E Gêmeos: mórbida semelhança deriva do romance Twins (1977), de Jack Geasland e Bari Woods. Além disso, ele dirigiu adaptações roteirizadas por outros como: A hora da zona morta, do romance de Stephen King; M. Butterfly, da peça de David H. Hwang; Spider: desafie sua mente, do romance de Patrick McGrath e Marcas da violência, adaptação da graphic novel de John Wagner e Vince Locke. E Mistérios e paixões, adaptação de Almoço nu (1959), de William Burroughs, Crash: estranhos prazeres, adaptação de Crash (1973), de James G. Ballard, e Cosmópolis (2003), de Don DeLillo, que devem ser destacados por serem roteiros de autoria do próprio cineasta.
} 
Menard para escrever Quixote. Uma vez que tal como Menard, que tenta resgatar todas as condições e influências que levaram Cervantes a escrever Quixote; Cronenberg mergulha nas condições que levaram Burroughs a escrever sua novela, através de sua biografia e de sua produção textual, para recriar Almoço nu. Menard primeiro pensara em ser Cervantes, mas depois percebeu que ser Cervantes e chegar ao Quixote seria menos árduo e menos interessante que continuar sendo Menard e chegar ao Quixote. E se Menard conhecia muito bem a obra do autor que traduzia, Cronenberg igualmente é um leitor aficionado da obra de Burroughs e essas leituras também se fizeram presentes quando da escrita do roteiro: "Durante la escritura del guión, tenia cinco de sus libros sobre mi mesa y de tiempo en tiempo abria uno al azar y leia un pasaje para captar el ritmo, el tono de la escritura" (CRONENBERG apud GOROSTIZA, 2003, p. 227).

Mas, apesar de tanto Menard quanto Cronenberg imergirem no universo criativo do autor que reescrevem, nenhum é fiel ao texto original, pois se imbricam ao texto que transcriam. Ambos querem a autoria do texto que reescrevem. Assim como Menard que desistiu de tentar ser Cervantes para escrever seu Quixote, Cronenberg não queria ser Burroughs, mas desejava fundir-se artisticamente a ele, unindo suas identidades criativas em uma obra que nem um ou outro poderia ter criado sozinho. E ele justifica esse desejo a partir de "O enigma de Edward Fitzgerald", de Borges:

It's like the Rubaiyat of Omar Khayyam. Borges has written a wonderful critical essay on that poem, saying that the English translator, Edward Fitzgerald, was no good as translator because his work on the Rubaiyat is very faulty; that Khayyam was actually not a very good poet. But somehow, over the span of nine centuries, they combined to make this little gem of a poem that would never have happened otherwise (CRONENBERG, 1997, p. 162). 
O cineasta cita o texto de Borges para explicar a própria ação de tradutor do romance de Burroughs, pois, assim como Menard, ele descobre que a tradução literal é impossível:

When I transcribed word for word a sentence of description of the giant centipede, and then continued on with the next sentence to describe the scene in that I felt was a sentence Burroughs himself could have written, that was a fusion [...] It's like Burroughs and myself fusing in the telepod of The Fly. (CRONENBERG, 1997, p. 163). ${ }^{6}$

Mas, ao contrário do escritor fictício, ele encontra outra opção, a de fundir-se a Burroughs para conseguir trazer elementos de Almoço nu para a tela (CRONENBERG, 1997, p. 161). E, assim como o narrador do conto borgiano achava ser "lícito ver no Quixote 'final' uma espécie de palimpsesto, no qual devem transluzir os rastros - tênues, mas não indecifráveis - da 'prévia' escrita" (BORGES, 1989, p. 38) de Menard, é possível ver no filme de Cronenberg os rastros de sua pré-existência no livro de Burroughs. E é na tentativa de percorrer esses rastros, de "exumar e ressuscitar essas Tróias” (BORGES, 1989, p. 38), que se desvela o processo de adaptação de Almoço nu.

A ligação entre a obra de Burroughs e a de Cronenberg é, porém, anterior à realização do filme. E para o cineasta isso decorre de ambos serem very interested in metamorphosis or transformation (CRONENBERG, 1992, p. 12). Há uma notória confluência anterior a Mistérios e paixões. Micht Tuchman destaca elementos dos primeiros filmes do cineasta que revelam esse diálogo: os parasitas de Calafrios lembram as criaturas de Almoço nu e, em ambas as obras, esses seres invadem o corpo humano através dos órgãos

\footnotetext{
${ }^{6}$ Cronenberg refere-se aqui à fusão que acontece em seu filme $A$ mosca, no qual o DNA de um homem é fusionado ao de uma mosca, dando origem a um ser híbrido e diferente de ambos.
} 
genitais; o tecido "morfologicamente neutro" de Enraivecida na fúria do sexo, que se transforma em um tentáculo sanguessuga, parece ser o mesmo "tecido indiferenciável", apresentado por Burroughs, que pode crescer em qualquer carne, fazendo brotar órgãos sexuais; e a telepatia, tema central de Scanners, é também uma obsessão de Burroughs. Para Tuchman, as relações são tantas que, without Burroughs, Cronenberg may be without imagery (TUCHMAN apud CRONENBERG, 1997, p. 157).

No entanto, mais do que uma relação de influência há uma relação de conexão de imaginários, e nasce do reconhecimento dessa confluência a atração do Cronenberg pela obra de Burroughs, que culminou com a realização de Mistérios e paixões, um amalgama tão eficiente entre a obra dos dois que é quase impossível distingui-las. A angústia primordial em relação à influência, do tempo em que o cineasta pretendia ser escritor, é substituída pela noção de intertextualidade e pela consciência de que o filme, mais que uma adaptação do texto literário, é o resultado de um diálogo entre o seu universo artístico e o do escritor. Instaura-se então um jogo entre a memória e o esquecimento das leituras dos textos de Burroughs que impregnam a criação do cineasta, que deles se apropria e os reconfigura.

Para Cronenberg, o material do filme:

[...] was in Burroughs. Not all of it. Not all of it in Burroughs, and not all of it in me. But so much of it, right there, stuff I could have written, except Burroughs had been doing it so much better and so much longer (CRONENBERG, 1997, p. 162).

Novamente, confluindo com a percepção de Menard, uma vez que ambos acreditam que podem criar sem copiar o texto que já havia sido escrito. Pois, como explica o narrador do conto, mesmo Menard reproduzindo literalmente o texto de Cervantes, ambas as obras são essencialmente diferentes e a diferença resulta das ex- 
periências de cada um dos escritores, de seus diferentes contextos socioculturais e de suas diferentes leituras.

$\mathrm{Na}$ transcriação fílmica do texto de Burroughs, Cronenberg revela sua identidade artística. E assim, mesmo quando o material do romance se evidencia, sua marca autoral também se faz presente na escolha, no recorte, na apropriação e na forma como utiliza esse material. E é a partir dessa interrelação que Cronenberg define seu filme: I think of it as the product of a dream I would have about Burroughs and his book, a dream to which I bring all my particular obsessions and idiosyncrasies. (CRONENBERG apud BROWNING, 2007, p. 127).

A adaptação realizada por Cronenberg não busca a tradução fiel, mas sim a "recriação, ou criação paralela" (CAMPOS, 1992, p. 35) que nasce de uma identificação profunda com a obra que traduz, em confluência à proposta de Augusto de Campos:

\author{
Recriar é uma meta \\ de um tipo especial \\ de tradução: \\ a tradução-arte \\ mas para chegar à \\ re-criação \\ é preciso identificar-se \\ profundamente \\ com o texto original \\ (CAMPOS, $1986,2^{\circ}$ orelha)
}

Cronenberg transcria intersemioticamente em uma perspectiva borgiana, praticando uma leitura infiel criadora, que imbrica elementos de sua própria obra ao texto que lê. A ação do cineasta corrobora a perspectiva de Robert Stam que vê o texto original como "uma densa rede informacional, uma série de pistas verbais que o filme que vai adaptá-lo pode escolher, amplificar, ignorar, subverter ou transformar" (STAM, 2006, p. 50). Assim, apesar de gerado de material literário de outro autor, Mistério e paixões é 
um filme cronenberguiano, que vai além do próprio texto e faz da vida do escritor material para o filme, amalgamando vida e obra, misturando sem hierarquia textos ficcionais, cartas, entrevistas e dados biográficos. O vício em drogas, a dificuldade em lidar com a própria homossexualidade e a morte da mulher, ajudam a compor uma versão ficcional da jornada que levou Burroughs à literatura. Mais que uma adaptação de Almoço nu, o filme é sobre Burroughs, sua obra e seu processo de criação, mas é também um filme sobre a relação entre sua obra e a de Cronenberg. Um filme a respeito da criação literária e cinematográfica, que pode ser lido como uma metanarrativa que apresenta e investiga o processo de criação de Almoço nu e de transcriação de Mistérios e paixões.

\section{Referências}

BEARD, William. The Artist as Monster: The Cinema of David Cronenberg. Toronto: University of Toronto Press, 2006.

BORGES, Jorge Luis. Ficções. Tradução de Carlos Nejar. $5^{\circ}$ ed. São Paulo: Globo, 1989.

BROWNING, Mark. David Cronenberg: author or film-maker? Bristol, RU/ Chicago - EUA: Intellect Books, 2007.

BURROUGHS, William. Naked Lunch. Nova Iorque: Grove Press, 2001.

CAMPOS, Augusto. O anticrítico. São Paulo: Companhia das Letras, 1986.

CAMPOS, Harold. Metalinguagem e outras metas. 4a. ed. São Paulo: Perspectiva, 1992. 
CRONENBERG, David. Cronenberg on Cronenberg. $2^{\mathrm{a}}$ ed. London: Faber and Faber, 1997. (Entrevista concedida a Chris Rodley)

CRONENBERG, David. David Cronenberg. Sight and Sound. Londres, p. 1113, mar. 1992. Disponível em: http://www.davidcronenberg.de/snsint92.html Acessado em 23 jun. 2015. (Entrevista concedida a Mark Kermode)

GOROSTIZA, Jorge; PÉREZ, Ana. David Cronenberg. Madrid: Cátedra, 2003.

HUTCHEON, Linda. Uma teoria da adaptação. Tradução de André Cechinel. Florianópolis: Ed. da UFSC, 2011.

PLAZA, Julio. Tradução intersemiótica. São Paulo: Perspectiva, 1987.

SANTAELLA, Lucia. Transcriar, transluzir, trasnlucifera: a teoria da tradução de Haroldo de Campos. In: MOTTA, Leda Tenório da. Céu acima: para um tombeau de Haroldo de Campos. São Paulo: Perspectiva, 2005. (Col. Signos, n. 45)

STAM, Robert. Teoria e prática da adaptação: da fidelidade à intertextualidade. In: Ilha do desterro. $\mathrm{N}^{\circ}$ 51. Florianópolis: UFSC, 2006. p. 19-53. Disponível em: https://periodicos.ufsc.br/index.php/desterro/article/view/21758026.2006n51p19/9004 Acessado em 24 out. 2015.

TIRARD, Laurent. Grandes diretores de cinema. Tradução de Marcelo Jacques de Moraes. Rio de Janeiro: Nova Fronteira, 2006.

\section{Filmografia}

A mosca. Direção: David Cronenberg. Canadá, Estados Unidos: Brooksfilme, 1986. DVD (96 min), son., color., legendado. Tradução de: The Fly 
Calafrios. Direção: David Cronenberg. Canadá: Cinépix, 1975. DVD (87 min), son., cor., legendado. Tradução de: Shivers

Crash: estranhos prazeres. Direção: David Cronenberg. Canadá, Inglaterra: Aliance Communications Corporation, 1996. DVD (100 min), son., cor., legendado. Tradução de: Crash

Enraivecida na fúria do sexo. Direção: David Cronenberg. Canadá: Cinépix, 1976. DVD (91 min), son., cor., legendado. Tradução de: Rabid

eXistenZ. Direção: David Cronenberg. Canadá, Inglaterra: Alliance Communications Corporation, 1999. DVD (97 min), son., cor., legendado.

Mistérios e Paixões. Direção: David Cronenberg. Canadá, Inglaterra: Film Trustees Ltd., 1991. DVD (115 min), son., cor., legendado. Tradução de: Naked Lunch

Videodrome: síndrome do vídeo. Direção: David Cronenberg. Canadá: Famous Players, 1983. DVD (87 min), son., cor., legendado. Tradução de: Videodrome

Recebido em: 03/11/2015 Aceito em: 18/01/2016 Publicado em maio de 2016 